\title{
A 4D GIS methodology to study variations in evaporation points on a heritage building
}

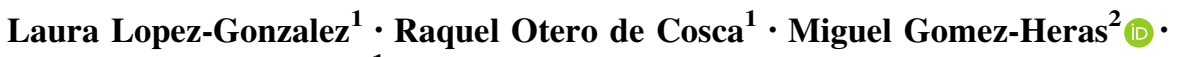 \\ Soledad Garcia-Morales ${ }^{1}$
}

Received: 26 February 2016/Accepted: 18 July 2016/Published online: 25 July 2016

(C) Springer-Verlag Berlin Heidelberg 2016

\begin{abstract}
Building decay is a dynamic process in which time is a key factor, and moisture-induced decay is no exception to the rule. Mapping strategies may hinder timebased moisture damage assessment and control in historic buildings, however. The time factor has often been absent in the mapping methodologies deployed to date, either because the studies conducted were one-off exercises or no georeferencing was involved. This paper describes the generation of four-dimensional space from a three-dimensional geographic information system (GIS) and time series data and its use to assess the incidence of moisture, defined in terms of evaporation points, on a historic building. Taken together with the potential inherent in the application of map algebra to GIS, this approach constitutes a powerful tool for enhancing the interpretation of dynamic processes such as moisture flows and evaporation.
\end{abstract}

Keywords Stone decay · Geographic information systems $\cdot$ Hygrothermal behaviour $\cdot 4 \mathrm{D}$ mapping

This article is part of a Topical Collection in Environmental Earth Sciences on "Geomaterials used as construction raw materials and their environmental interactions" guest edited by Richard Prikryl, Ákos Török, Magdalini Theodoridou, and Miguel Gomez-Heras.

Miguel Gomez-Heras

miguel.gomez.heras@gmail.com

1 Escuela Técnica Superior de Arquitectura de Madrid, Universidad Politécnica de Madrid, Madrid, Spain

2 Instituto de Geociencias (CSIC, UCM), Madrid, Spain

\section{Introduction}

Building stone decays, i.e., slowly deteriorates by environmental factors. This is an inevitable consequence of placing a material in an environment substantially different to the one it was formed in. While inevitable, such decay is obviously undesirable in historic buildings, for it detracts from the mechanical performance or aesthetics of the material, or both.

Building stone decay is a dynamic process in which time may well be the key factor. Nireki (1980) identified the assessment of performance over time as crucial to determining durability. An in-depth understanding of stone behaviour over time (the factors that trigger and govern decay and the behaviour of different types of stone in varying environments) is requisite to retarding the initiation and progression of stone decay as well to conserving decaying stone (Smith et al. 2008). In this sense, monitoring decay and decay agents over time is crucial for preemptive conservation strategies.

It is well known moisture is one of the major causes of building material and structural decay (e.g., Sandrolini and Franzoni 2006; D'Agostino 2013). Moisture alters building material's structure and composition (e.g., Franzini et al. 2007; Benavente et al. 2008), as well as being a vehicle for soluble salts-a widely recognised decay factor-(e.g., Steiger and Siegesmund 2007 and subsequent papers of this special issue on salt decay of Environmental Geology). A spatial assessment of areas affected by damp and moisture (and their variations) is crucial to the effective monitoring and control of moisture in buildings. That entails assessing evaporation points that depend on the location of moist areas and the impacts of the indoor environment. Evaporation points are also areas particularly prone to decay factors, such as salt decay. 
Graphically representing the findings of the hygrothermal, electric and gravimetric methods used to study moisture in historic buildings is hardly straightforward. The graphic outputs of each instrument's software are normally overlaid on two-dimensional drawings of the building. Alternatively, the data obtained are simply positioned to the author's criteria, more or less precisely, on a two-dimensional architectural or survey drawing. In neither approach are the data georeferenced.

Moreover, moisture data are normally shown as a twodimensional snapshot. Very few studies that map evaporation points over time, especially for periods of over $24 \mathrm{~h}$, are to be found in the literature. In one such study, authored by Hutton (1996), the fluctuations in indoor temperature and relative humidity were related to hygrothermal variations in the outdoor air using automatic thermo-hygrometer data loggers.

Other examples are to be found in Camuffo's (2014) two-dimensional RH (\%) and temperature contour maps, and in D'Agostino's (2013) likewise 2D contour maps of the theoretical distribution of evaporation found by interpolation and overlaid on plan drawings of buildings with ArcView software. As both studies were conducted on a single day, however, the respective maps depict that period of time only. That does not suffice to determine the pattern of moisture variations in historic buildings, a factor instrumental to establishing a correct diagnosis. Other studies (such as Martinez-Garrido et al. 2014) mapped walls only partially on the grounds of non-georeferenced moisture meter data or determined long-term variations with single-site sensors from which maps cannot be drawn. García Morales et al. (2012), in turn, defined a 'maximum evaporation intensity factor $\left(F_{\mathrm{i} \max }\right)$ ' function for cartographic evaporation modelling. Although their survey covered a long period of time, only one two-dimensional map was ultimately generated, with the most representative points identified in the analysis.

Digital multi-image photogrammetry encompasses the high accuracy needed when documenting measurements in any cultural heritage item. Three-dimensional dense 'point clouds' can be generated through photogrammetry. These point clouds resemble those obtained with more expensive-and often leading to less detailed representationslaser scanner (e.g., Columbu and Verdiani 2014; GomezHeras et al. 2014). This, in turn, allows all stakeholders to access easily to a useful and powerful representation of the heritage item.

López-González (2016) showed that by applying geographic information systems (GIS) to the built heritage, two-dimensional drawings can be replaced with three-dimensional georeferenced maps of both the element studied and the analytical data collected. A GIS is a combined hardware and software system that uses georeferenced geographic information in conjunction with layered databases which while separate, can be interrelated. These layers can generate new layers of information as the study and the problem addressed progress. In the present study, the georeferenced base map was the digital three-dimensional model of the wall of a sixteenth century chapel and the successive layers of information were the results of the tests conducted (data maps). The use of GIS in heritage studies follows the recommendation of promoting 'the use of modern technologies, databanks, information system and virtual presentation techniques' given by the Charter of Cracow (2000) and subsequent Charters (such as London 2006, ICOMOS 2008 and Brussels 2009) for the conservation of built heritage.

Adding time to the three spatial dimensions $X, Y$ and $Z$, a four-dimensional space (4D) is obtained. The term $4 \mathrm{D}$, used to designate this long-standing mathematical and physical concept, has become increasingly popular in imaging and graphics parlance in recent years. It has been embraced in GIS technology, heritage and masonry studies and surveying, among others, to signify an approach to data acquisition in which information is logged at different points in time to visualise change in territorial or structural parameters (Van Ruymbeke et al. 2008; Doulamis et al. 2013; Bertolla et al. 2014; Mezzino 2014; Raimondi et al. 2014).

GIS tools, in turn, can be used to formulate as many data layers over time as required, thereby converting 3D to 4D space. Moreover, as GIS is able to operate with the various layers of data, new information can be gleaned from a given time series.

This paper aims to show that the inclusion of time series data in GIS improves its potential as a way of representing built heritage decay processes and as a tool for pre-emptive conservation. This is shown through an example of evaporation point-based assessments of the incidence of moisture by applying map algebra to GIS technology to add new layers of information to survey findings.

\section{Methods}

\section{Case study}

The decay features detected on the 'Ermita del Humilladero' at Avila, Spain, along with its size and construction, determined its choice as the object of this case study.

This chapel (Fig. 1), built between 1548 and 1550, has two wythes of granite ashlars. The space between the interior and exterior wythes is filled with an unknown material. The building has a square (approximately $106 \mathrm{~m}^{2}$ ) floor plan and granite buttresses on all four corners. As the street elevations along the north and west are 

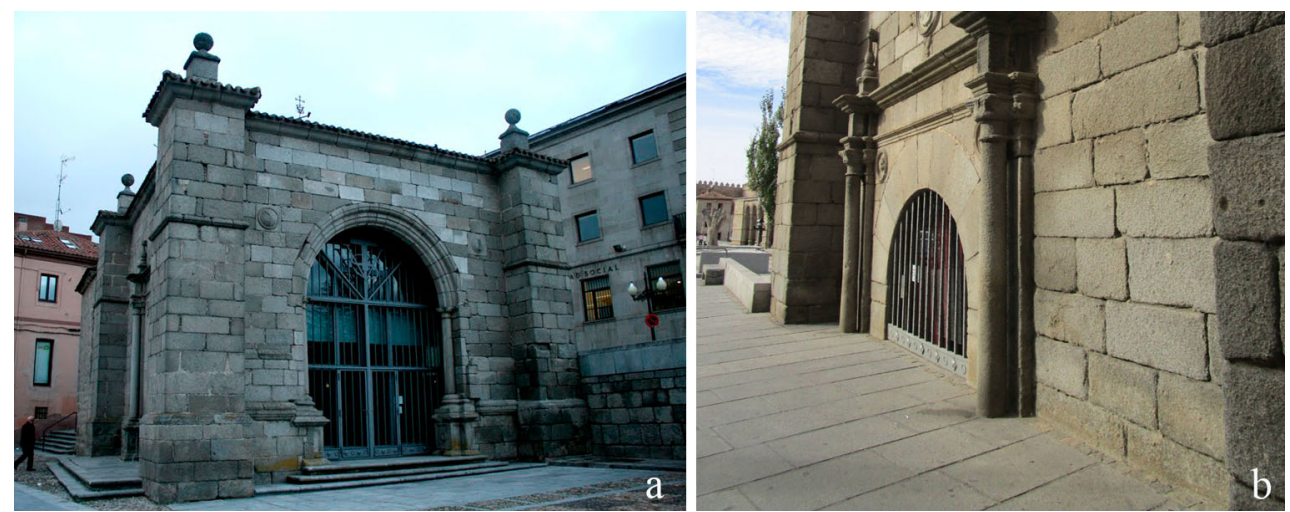

Fig. 1 a N-W view of the chapel. b South wall

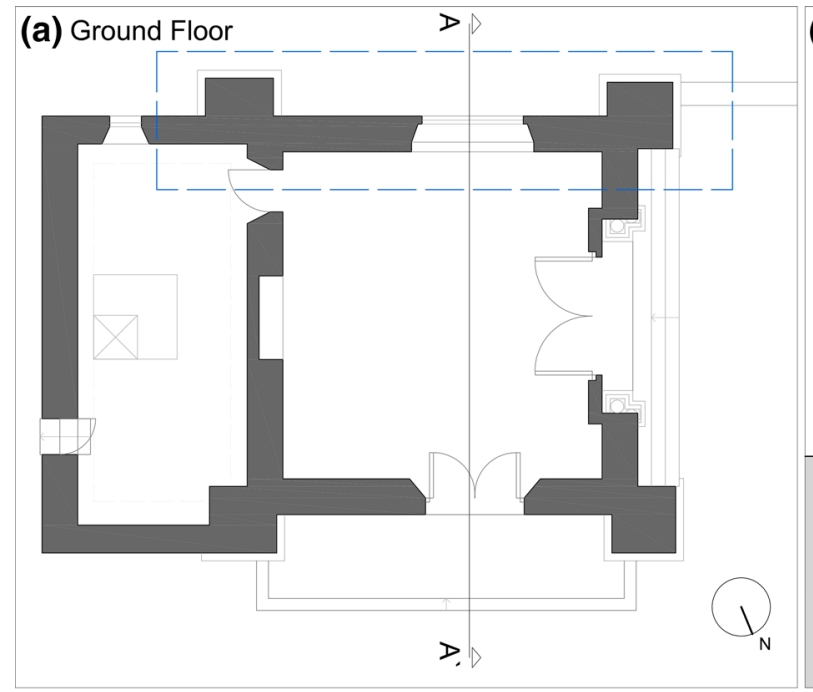

(b) Cross-section $A A^{\prime}$

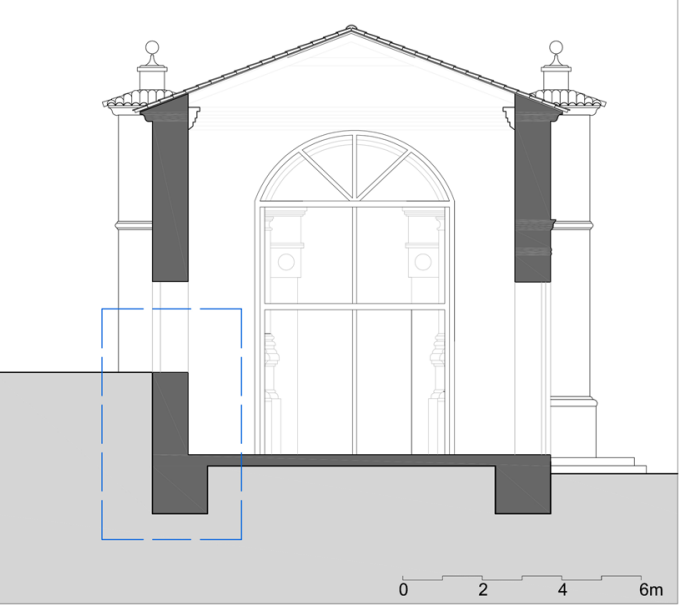

Fig. 2 a Ground storey showing the partially interred wall where data were collected; b cross section showing the partially interred wall (dashed line)

lower than on the south façade, this wall lies partially underground. The unceilinged sacristy attached to the east façade was built in a subsequent phase of construction using irregular granite ashlars. When a basement was dug underneath its semi-interred ground storey in 1990, the existing foundations were strengthened with concrete (Morales Dos Ramos 2014).

The north and west façades have identically sized doors, whereas the sole opening on the south wall is a window. The indoor setback in this section of wall, which under and above the window consists of a single wythe approximately $20 \mathrm{~cm}$ thick, suggests that it may have once housed a door, subsequently converted into the present window.

The study focused on the south façade where damp damage was observed (Fig. 2). Although the adjacent walkway is suitably sloped to empty rainwater onto the carriageway, a few puddles near the wall were observed to take some time to dry, possibly due to water accumulating underneath the pavement. Moreover, on the days after it rains, some areas of the floor inside the building along the south wall remain visibly wet.

\section{Photogrammetry}

Single image photogrammetry was used to obtain a threedimensional digital model of the wall. This technique consists in obtaining planes or point clouds of an object with rectified photographs of the object taken from different angles and processed with specific software. Today the method is widely used given its lower cost than techniques such as three-dimensional laser scanning (Almagro 2011) and the development of software able to deliver nearly three-dimensional laser scan accuracy (Jordá et al. 2011) (Fig. 3).

In this study, eight sequence photographs were taken parallel to the wall at a constant height with a $10.2 \mathrm{MP}$ 
Fig. 3 Interior of the semiinterred south wall where data were collected
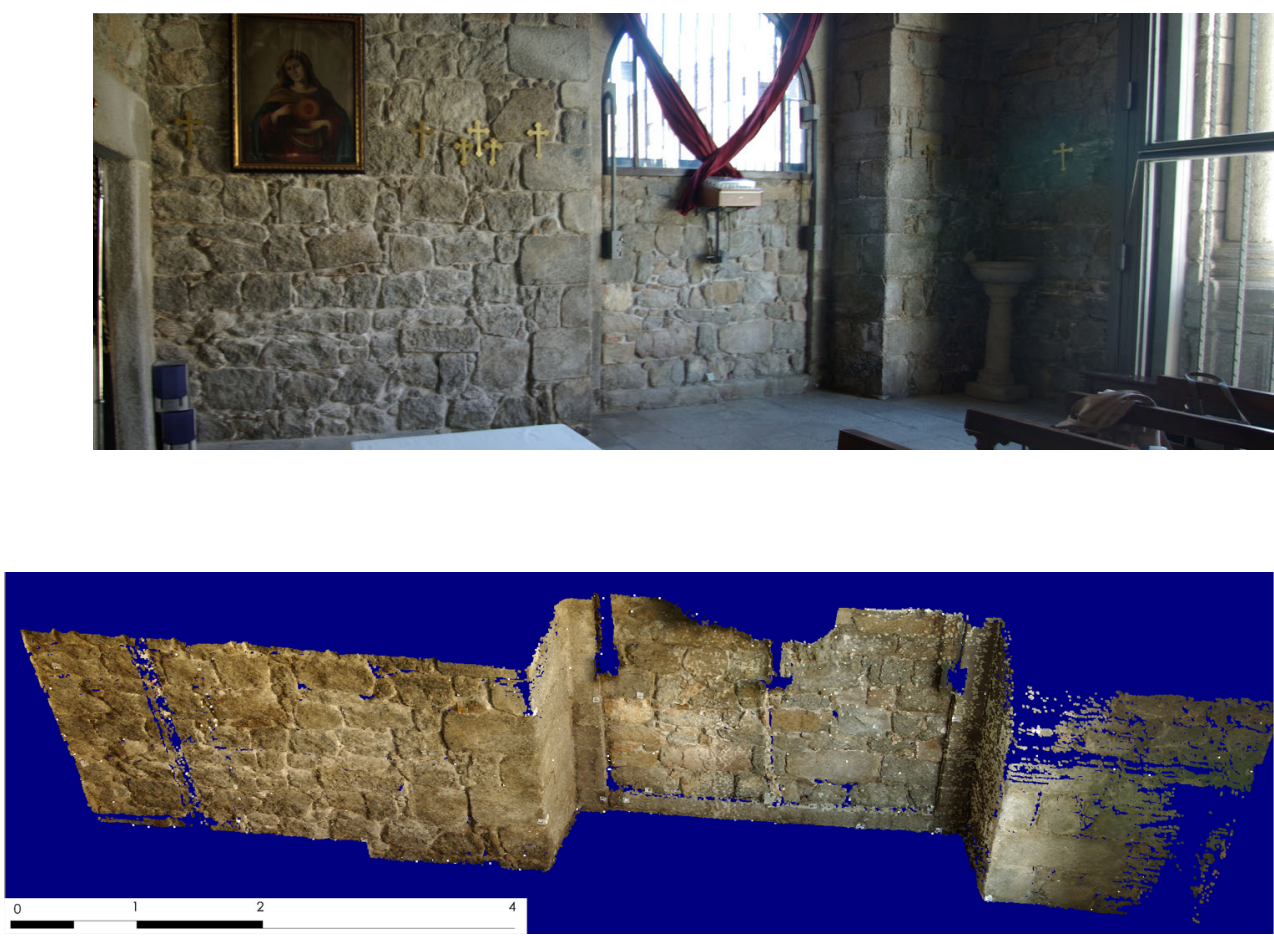

Fig. 4 Initial three-dimensional point cloud modelling

humidity ratio $(\mathrm{g} / \mathrm{kg}), \mathrm{W} \%$ is humidity ratio $(\%)$ and $\mathrm{t}_{\mathrm{dew}} \%$ is dew temperature (\%). In addition to this, it is specified if the point was measured on a stone block or on a mortar joint $\mathrm{t}$ is air temperature $\left({ }^{\circ} \mathrm{C}\right), \mathrm{t}_{\mathrm{dew}}$ is dew temperature $\left({ }^{\circ} \mathrm{C}\right), W$ is

Attributes associated to the shapefile

\begin{tabular}{llllllllll}
\hline Point number & \multicolumn{2}{l}{ Coordinates } & & $\mathrm{t}_{\mathrm{air}}$ & $\mathrm{t}_{\mathrm{dew}}$ & $\mathrm{W}$ & $\mathrm{W} \%$ & $\mathrm{t}_{\mathrm{dew}} \%$ & Measured on stone \\
& $\mathrm{X}$ & $\mathrm{Y}$ & $\mathrm{Z}$ & & & & & &
\end{tabular}

$(3872 \times 2592$ P) Pentax KD10 SLR camera with CCD sensor and an 18- to 55-mm lens. Pictures were taken at a $2-\mathrm{m}$ distance from the wall with the $18-\mathrm{mm}$ lens and varying the shooting angle, so there was enough overlap between consecutive pictures. Reference axes were determined using 17 eight- and twelve-bit coded targets positioned at the corners of the wall panels. In addition, 450 natural targets (i.e., singular points in the pictures, such as triple joints), were established for further referencing.

Photogrammetry conducted with PhotoModeler Scanner (6.2.2.596) software generated a digital model of the wall, i.e., a three-dimensional georeferenced point cloud containing 769,532 points (Fig. 4). The existence of elements on the wall (such as curtains on adjacent windows or electrical wiring), however, left gaps in some sections of the cloud. The centre of the coordinates on one of the wall panels was determined for cloud scaling and orientation purposes. The $X$ axis was defined as the horizontal axis parallel to the wall, $Y$ as the vertical axis and $Z$ as the horizontal axis perpendicular to the wall. These coordinates were the base for GIS georeferencing.

\section{Generating digital surface models}

ArcGis 10.1 software with Spatial Analyst 10.1 module was used. The software-processed raster layers generated with the scaled and georeferenced point cloud yielded a digital surface model (DSM). The data in the point cloud were converted to a shapefile (.shp) vectorial digital storage file in which the location of the surface elements and their associated attributes are saved (see Table 1). The output was a new GIS visual point cloud where each point was identified by its coordinates and assigned a feature ID (FID) number, i.e., an indexed spatial element identifier. With this software, the FID and coordinates of any point on the model could be determined with a single click. Inverse distance weighted interpolation (with interpolation settings of minimum two and maximum four neighbour cells) of the.shp file data generated a highly accurate raster surface or layer, which included the gaps on the point cloud. A total of 769,532 points were used for the interpolation, and the cell size of the calculated raster was set to $0.2 \mathrm{~mm}$. Once the first raster layer was in place, it was hillshaded to better visualise texture. This technique was used to determine the 


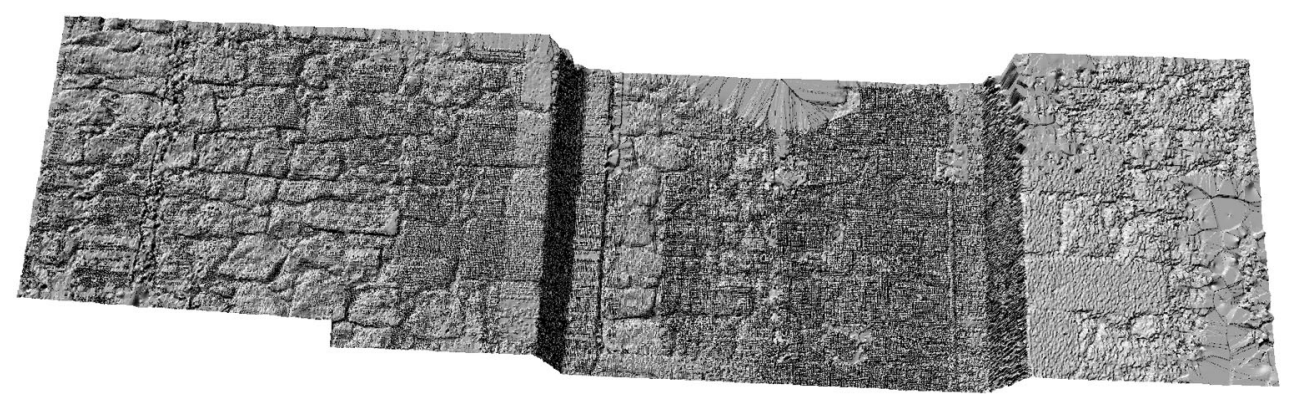

Fig. 5 Hillshade texturing of raster layer (generated from interpolation of digital surface model) revealing the individual ashlars that comprise the wall

illumination value for each raster cell and hence hypothetical surface illumination. The position of a hypothetical light source was defined (light source default settings: azimuth $=315$, declination $=45$ ) and the illumination for each cell relative to the adjacent cells was calculated. The new GRID raster layer created (Fig. 5) displayed the fully textured object, in which the degree of texturing was determined by the value defined for forced interpolation. Raster layer contrast revealed surface textures not visible to the naked eye or in photographs. The raster layer is the base map on which the data maps are overlaid.

\section{Hygrothermal inspection}

Two hygrothermal inspections were conducted a fortnight apart in February and March 2015. In this precipitation-free interval, the weather ranged from moderately cold (daily temperatures of $1-10{ }^{\circ} \mathrm{C}$ ) to freezing with widely ranging daily temperatures $\left(-5\right.$ to $20{ }^{\circ} \mathrm{C}$ ), as measured $2 \mathrm{~km}$ away from the building by a urban meteorological station managed by the Spanish meteorological agency. These months were chosen to observe the variations in evaporation points in an environment with steep thermal contrast and no rainfall. Evaporation intensity was measured at the points with two TESTO instant display digital thermo-hygrometers, models 601 and 625. Accuracy for both thermo-hygrometer models is $\pm 0.5{ }^{\circ} \mathrm{C}$ and $\pm 2.5 \% \mathrm{HR}$, while precision is $0.1{ }^{\circ} \mathrm{C}$ and $0.1 \% \mathrm{HR}$. Two operators used a thermo-hygrometer each to speed up the measurement process, which took approximately $2 \mathrm{~h}$ in total. Measurements were taken following the hygrothermal monitoring method proposed by García Morales et al. (2012). This method calculates the humidity ratio $(\mathrm{g} / \mathrm{kg})$ in the air in contact with the wall surface from the thermo-hygrometer measurements read at each point. The humidity ratio $(W)$ is a table-based measure of the absolute moisture content in air. Surface humidity ratios were compared to the indoor environment (taken as the reference value) to classify the evaporation points on the grounds of their 'evaporation intensity factor'. In this study, the evaporation intensity factor $(F)$ is defined as the difference between the maximum and minimum humidity ratios recorded with the thermo-hygrometers during the survey on the day the readings were taken. The data are also compared to the outdoor humidity ratio $\left(W_{\mathrm{o}}\right)$. The maximum indoor humidity ratio $\left(W_{\mathrm{i} \max }\right)$ is indicative of the general evaporation intensity measured in the building. The maximum indoor evaporation intensity factor $\left(F_{\mathrm{i} \text { max }}\right)$ is defined as the difference between the maximum humidity ratio measured and $W_{\mathrm{o}}(1)$. A certain 'absolute value' of humidity ratio in the air in contact with the wall may or may not indicate a humidity flux from the wall to the air depending on the specific environmental humidity of that building. Hence, points of intense evaporation are established by comparing the humidity ratio in the air in contact with the wall and indoor and outdoor environments.

$F_{\text {imax }}=W_{\text {imax }}-W_{\mathrm{o}}$.

Humidity ratio readings were taken both on ashlars and at inter-ashlar joints on the two dates further to an irregular data point grid (Fig. 6). Measurements were taken at both types of sites inasmuch as evaporation was expected to differ depending on whether the substrate was mortar or granite. Readings were taken by holding the thermo-hygrometer against the data point until the $\mathrm{T}$ and $\mathrm{RH}$ values stabilised (a few seconds). As, each measurement is taken individually, the number of operator together with the instrumental response rate determined the number of readings that could be taken in a single day.

\section{Overlaying hygrothermal data on digital surface models}

The readings were georeferenced on the GIS raster layer by identifying the data points on the layer to generate a new GIS vector layer specifying data point positions. The vector layer could then be used to group data points to different criteria, such as location on joints or stone surfaces, or the date of the reading. Further raster layers could be obtained from the georeferenced layer of points by applying IDW 


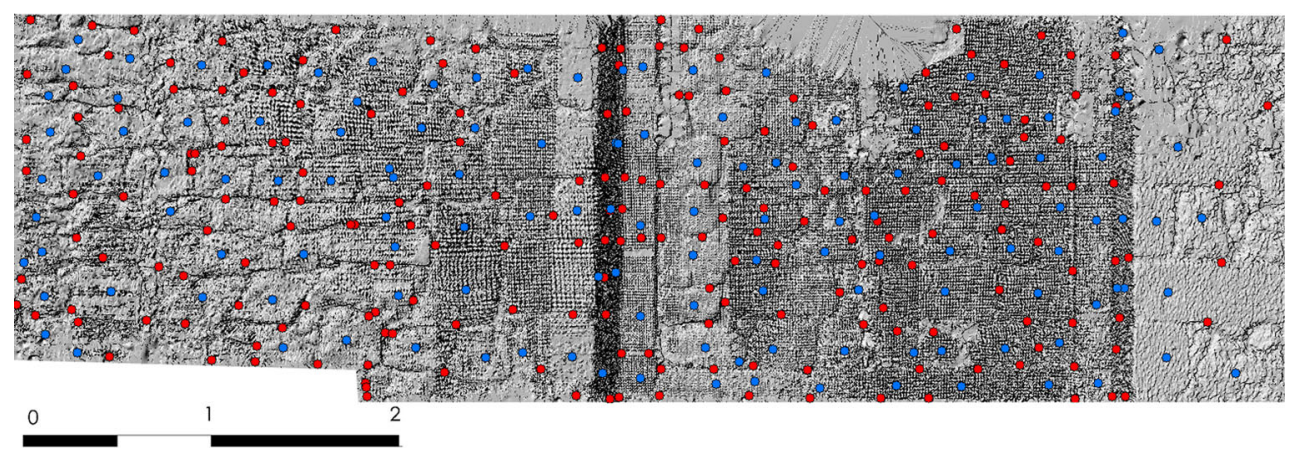

Fig. 6 Second day (12/03/2015) data points depicted on raster layer (hillshade map): red readings on joints; blue readings on stone; total readings: 210 in joints +139 on stone $=349$

Fig. 7 a and b show a comparison of thermohygrometer $W(\mathrm{~g} / \mathrm{kg})$ readings on joints on different dates (scales with identical intervals). $\mathbf{b}$ and $\mathbf{c}$ show the second day $W(\mathrm{~g} / \mathrm{kg})$ readings: b map based on joint readings only; c map based on stone surface readings only. Although evaporation was clearly less intense on the ashlars than on the joint surfaces, some decayed ashlars (such as the one identified with a red arrow in cexhibited greater evaporation than others (a)

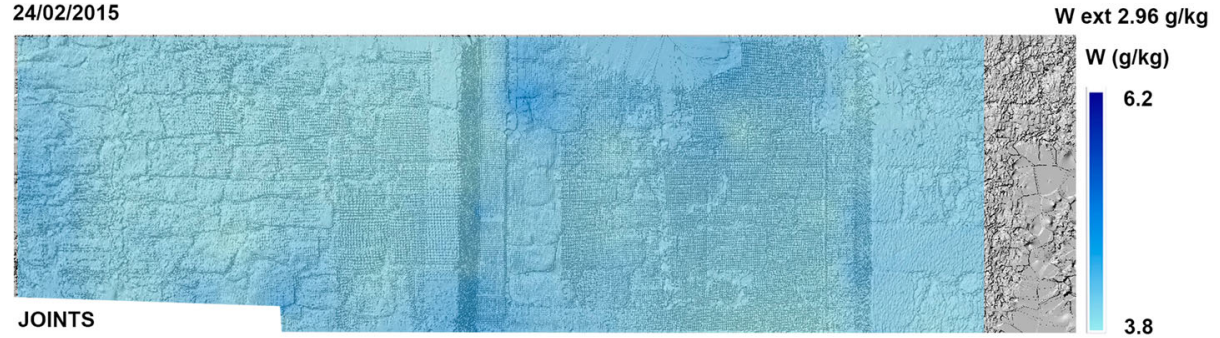

(b)

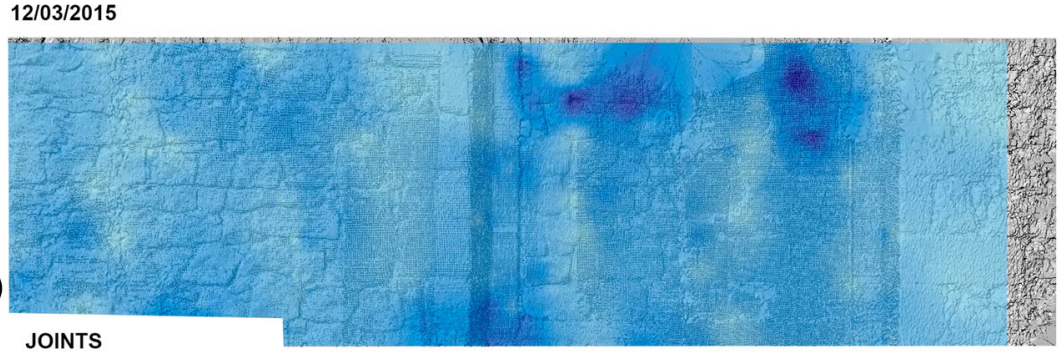

$W$ ext: 4.3 gkg W $(\mathrm{g} / \mathrm{kg})$

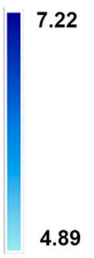

$12 / 03 / 2015$

$W$ ext: $4.3 \mathrm{~g} / \mathrm{kg}$

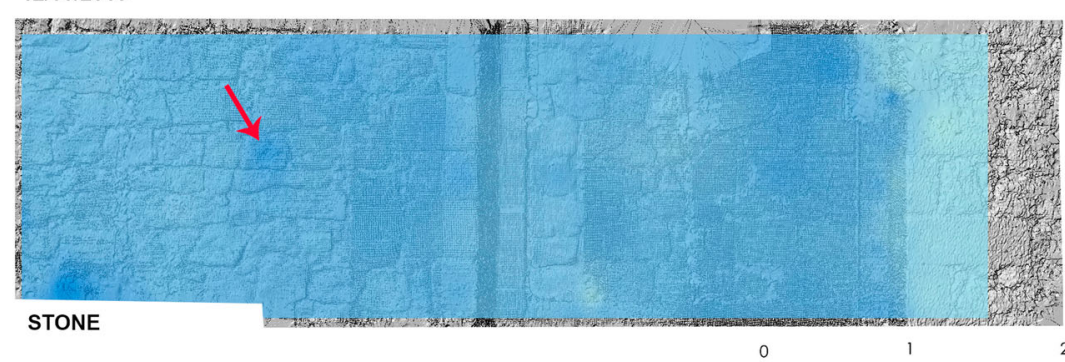

W $(\mathrm{g} / \mathrm{kg})$

7.22

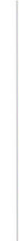

4.89 interpolation to the actual readings (with interpolation settings of minimum two and maximum four neighbour cells). IDW interpolations were made for each separate survey using all the thermo-hygrometer readings corresponding to that specific survey (79 points for the first survey campaign and 349 for the second). The cell size of the GRID raster was set to $3.6 \mathrm{~mm}$. With this method, although readings were taken at different data points on different days, the maps were comparable and could be manipulated jointly. Overlaying the raster layers on the hillshade image yielded a new, highly accurate two- and three-dimensional data map.

Nonetheless, the presence of widely varying $\mathrm{W}$ ranges may render the comparison of maps generated on different days impractical, inasmuch as using a common scale for the two maps might mask the relative prominence of evaporation points on each day. Consequently, in this study, the relative difference between the highest and lowest values on the scale was maintained, although the range changed (Fig. 7a, b). 
For the purposes of map algebra, the daily $\mathrm{W}$ values were converted to percentages (defining the lowest daily value of $W$ to be 0 and the highest 100) as observed in Fig. $8 \mathrm{a}$ and $\mathrm{b}$, and these percentages were then summed directly in the GIS. In other words, the sum of the two maps yielded a third in which the areas where evaporation was most intense on both days appear more prominently (Fig. 8c). Similarly, map algebra was deployed to subtract first day Ws from the second day values to identify the points that were most active overall (Fig. 8d).

\section{Results and discussion}

According to the maps of the $W$ values for the joints only (Fig. 7a, b), evaporation was much more intense on the second day than on the first. The first day was scarcely cloudy with gusty wind, and the outdoor temperature was $4.3^{\circ} \mathrm{C}$ (as measured with a data logger placed just outside the building). The second day was sunny, and the outdoor temperature during readings was $14{ }^{\circ} \mathrm{C}$. In both cases, evaporation was most intense in the centre (i.e., the most slender part) of the wall, primarily along a horizontal line
Fig. 8 a Day $1 W$, in $\%$; b day $2 W$ in \%; c sum of $W$ values for days 1 and 2; $\mathbf{d}$ day $2 W$ values minus day 1 values

\section{$24 / 02 / 2015$}

(a)

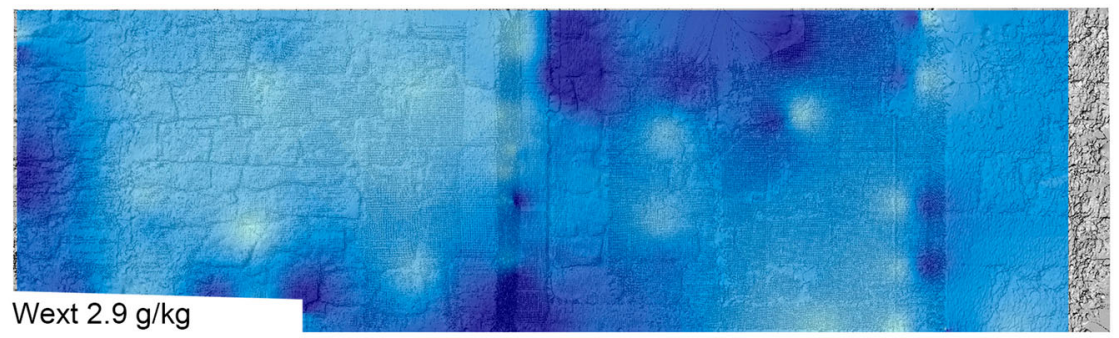
$W(\Delta \%)$

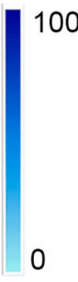

$12 / 03 / 2015$

(b)

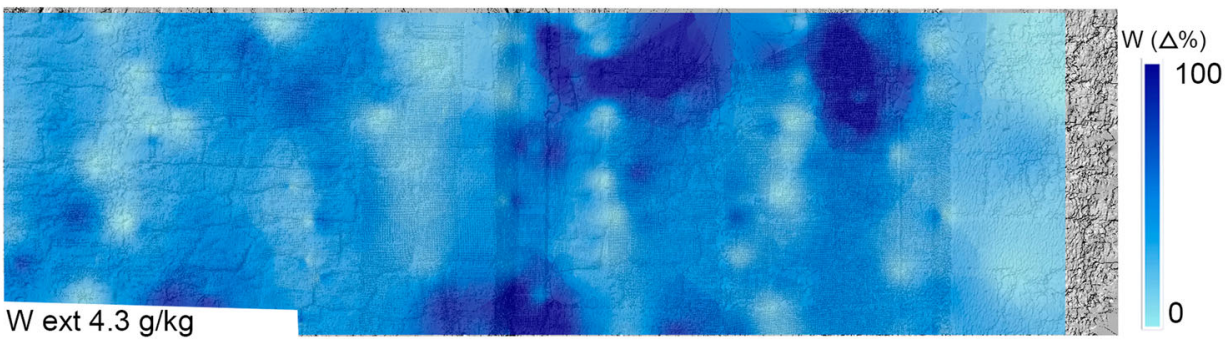

(c)

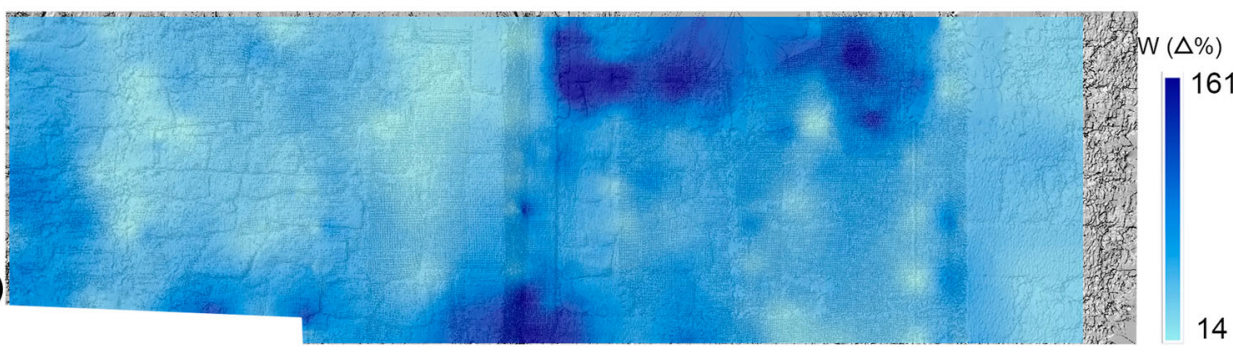

$24 / 02 / 2015$ plus $12 / 03 / 2015$

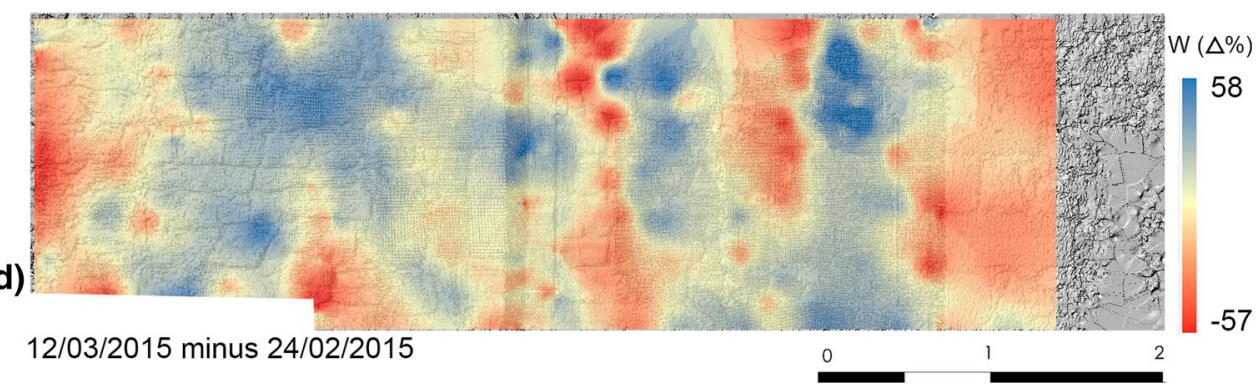


Fig. 9 3D hillshade map showing an overlap of the result of subtracting the 24/02/2015 IDW raster for the humidity ratio $(W: \mathrm{g} / \mathrm{kg}, \%)$ from the $12 / 03 / 2015$ raster

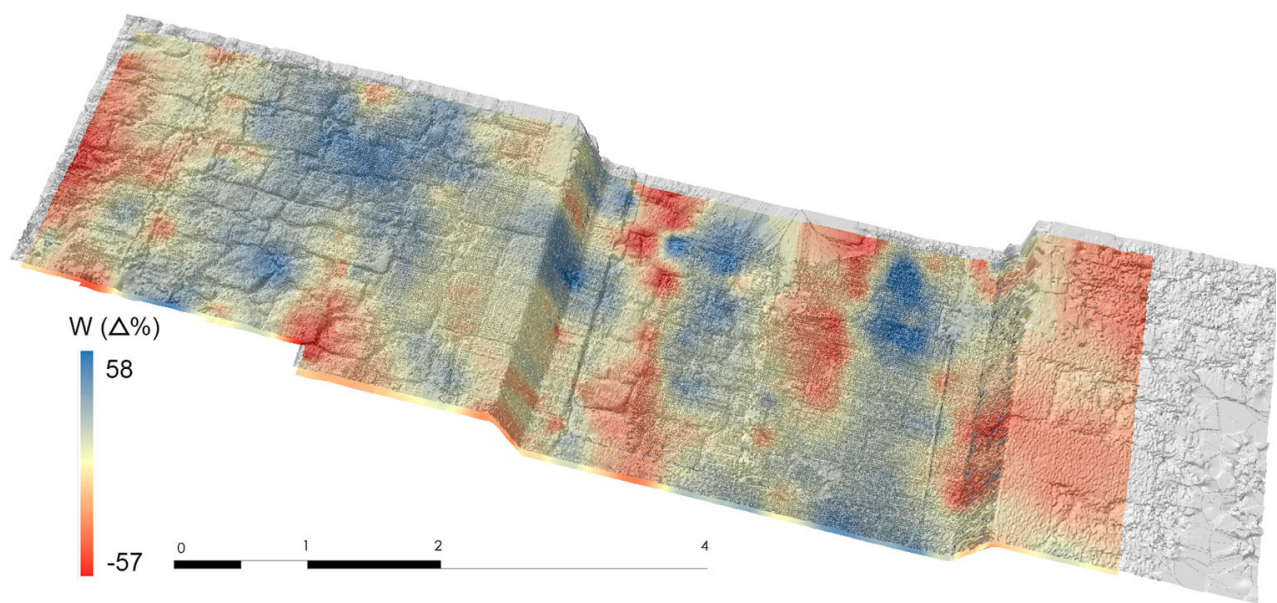

approximately $2 \mathrm{~m}$ off the indoor floor, immediately underneath the window and at the same elevation as the outdoor walkway; as well as on the left end of the area where the wall thickness changes, with higher values in the area closest to the floor.

The layout of the streets and buildings nearby the south wall together with the low winter sun angle prevents direct insolation during most part of the day. Nevertheless, insolation may still play a relevant role in terms of the more intense evaporation in the slender part of the wall, as even very localised differences in albedo and in insolation both in space and time may lead to relevant surface temperature differences (Gomez-Heras et al. 2008) that affect, after a lag time, to the inner core of walls (Martínez-Garrido et al. 2014).

Evaporation was greater in the mortar joints (Fig. 7b) than in the stone ashlars (Fig. 7c). Since evaporation on the latter was governed by the physical properties (primarily porosity) of each ashlar, the evaporation patterns there differed from the general norm. Consequently, only the joint readings, which exhibited a pattern more representative of the wall as a whole, were used to generate the graphic in Fig. 7a and $b$ and perform the map algebra calculations.

The areas with most intense evaporation on each day were more readily visible when the maps were re-scaled to convert each day's maximum evaporation to $100 \%$ (Fig. 8 a, b). The sum of the 2 days' readings (Fig. 8 c) highlighted the main evaporation points over time. This map exhibited two vertical strips along the entire left end of the wall where $\mathrm{W}$ values were lower, interrupted by areas with higher values. That would appear to indicate that evaporation behaved differently in there than in the rest of the wall as depicted on the maps for each day separately, perhaps denoting the presence of isolated water pockets behind the wall.

The map resulting from subtracting the first from the second day values (Fig. 8d) revealed the areas in which evaporation was most affected by the rise in outdoor temperature. This map shows that outdoor temperature affected the relative variations in evaporation along two vertical strips that concurred with the corners of the window located at the same elevation as the outdoor walkway. Moreover, relative evaporation rose in an area at the left end of the wall from which a series of arms radiated downward. At the interface between the wall and the floor, however, relative evaporation intensity declined along a series of vertical strips, suggesting that while this may be an area of ongoing evaporation, it is impacted less by variations in outdoor temperature.

With this technology, the digital model for the wall could be overlaid on GIS maps. The result, 3D maps (Fig. 9), afforded a clearer spatial view of the areas where evaporation was most intense on each day and facilitated their interpretation as the outcome of percolation to the surface through the wall and the ground.

\section{Conclusions}

GIS can be used to georeference data gathered at any given point on a surface of an object at different times with no need to pre-establish fixed grids that may be difficult to reproduce from 1 day to the next.

Overlaying test points on a GIS base map has proven to be a very useful and speedy mapping tool, which can be automatically generated with GIS software once the starting data are defined. This allows to different professionals working on heritage conservation to incorporate new information as studies progress and create an information system complying with the recommendations established in conservation charters.

Nonetheless, perhaps the most characteristic feature of GIS data mapping, particularly in the study of dynamic processes is that the resulting maps can be used to study the time factor. Different days' findings can be readily 
compared either by changing the scales used or deploying map algebra to clearly define the areas where most significant changes are taking place. Map algebra is also a tool to generate new information from data gathered by different professionals involved in building conservation.

In this study, as an example of application of this methodology, hygrothermal data were recorded and maps were generated for different types of materials, varying the scale over time. The data maps formulated identified the major evaporation points. The data for ashlars and joints were mapped in both absolute values and in percentage.

This case study verifies the importance of monitoring an element over time, an essential factor in planning preemptive conservation and detecting structural and material decay. With GIS technology, the behaviour of an element can be visualised more readily, facilitating the understanding and interpretation of the resulting patterns for the implementation of more effective conservation measures.

Acknowledgments This research was funded by the Regional Government of Madrid and the European Social Fund under the project Geomateriales 2 S2013/MIT-2914, as well as by the Territorial Culture Service of the province of Avila, Department of Culture and Tourism, Regional Government of Castile and Leon.

\section{References}

Almagro A (2011) Veintidós años de experiencia de fotogrametría arquitectónica en la Escuela de Estudios Árabes, CSIC. In: Domingo M, Sanchez AJ (eds) Documentación gráfica del Patrimonio. Ministerio de Cultura, Madrid, pp 26-45

Benavente D, Cultrone G, Gomez-Heras M (2008) The combined influence of mineralogical, hygric and thermal properties on the durability of porous building stones. Eur J Mineral 20:673-685

Bertolla L, Porsani JL, Soldovieri F, Catapano I (2014) GPR-4D monitoring a controlled LNAPL spill in a masonry tank at USP, Brazil. J Appl Geophys 103:237-244

Camuffo D (2014) Microclimate for cultural heritage. Elsevier, Amsterdam

Charter, of Cracow (2000) Charter of Cracow 2000: principles for conservation and restoration of built heritage. Archaeol Polona $38: 251-256$

Columbu S, Verdiani G (2014) Digital survey and material analysis strategies for documenting, monitoring and study the romanesque Churches in Sardinia, Italy. Lecture notes in computer science, vol 8740, pp 446-453

D'agostino D (2013) Moisture dynamics in an historical masonry structure: The Cathedral of Lecce (South Italy). Build Environ 63:122-133

Doulamis A, Ioannides M, Doulamis N, Hadjiprocopis A, Fritsch D, Balet O, Julien M, Protopapadakis E, Makantasis K, Weinlinger G, Johnsons PS, Klein M, Fellner D, Stork A, Santos P (2013) 4D Reconstruction of the past. In: Hadjimitsis DG, Themistocleous K, Michaelides S, Papadavid G (eds) Proceedings of SPIE Volume: 8795 First International Conference on Remote Sensing and Geoinformation of the Environment. Article Number: UNSP $87950 \mathrm{~J}$

Franzini M, Leoni L, Lezzerini M, Cardelli R (2007) Relationships between mineralogical composition, water absorption and hydric dilatation in the "Macigno" sandstones from Lunigiana (Massa, Tuscany). Eur J Mineral 19:113-123

García Morales S, López-González L, Collado Gómez A (2012) Metodología de inspección higrotérmica para la determinación de un factor intensidad de evaporación en edificios históricos. Informes de la Constr 64:69-78

Gomez-Heras M, Smith BJ, Fort R (2008) Influence of surface heterogeneities of building granite on its thermal response and its potential for the generation of thermoclasty. Environ Geol $56: 547-560$

Gomez-Heras M, López-González L, García-Morales S, Fort R, Álvarez de Buergo M (2014) Integrating non-destructive techniques with photogrammetry 3D models for the development of geographic information systems in heritage structures. In: Rogerio-Candelera MA (ed) Science, technology and cultural heritage. Taylor \& Francis Group, London, pp 429-434

Hutton T (1996) Monitoring Britaińs heritage. Constr Repair 10(1):41-42, 44

Jorda F, Navarro S, Pérez A, Cahero R, López D, Lerma JL (2011) Close range photogrammetry and terrestrial laser scanning: high resolution texturized 3D model of the Chapel of the Kings in the Palencia cathedral as a case study. ISPRS. CIPA Symposium

López González L (2016) Aplicación de herramientas GIS para la cartografía y correlación de datos de ensayos no destructivos en el diagnóstico de edificios históricos. Unpublished $\mathrm{PhD}$ Thesis. Universidad Politécnica de Madrid. Escuela Técnica Superior de Arquitectura

Martinez-Garrido MI, Gomez-Heras M, Fort R, Varas-Muriel MJ (2014) Monitoring moisture distribution on stone and masonry walls. In: Rogerio-Candelera MA (ed) Science, technology and cultural heritage. CRC Press, Boca Raton, pp 35-40

Martínez-Garrido MI, Aparicio S, Fort R, Anaya JJ, Izquierdo MAG (2014) Effect of solar radiation and humidity on the inner core of walls in historic buildings. Constr Build Mater 51:383-394

Mezzino D (2014) The digitalization of Cultural Heritage's tangible \& intangible dimensions. In: Piscitelli M (ed) Best practices in heritage conservation and management: from the world to pompeii, Le vie dei Mercanti XII Forum Internazionale di Studi. La scuola di Pitagora editrice, Napoli, pp 115-122

Morales Dos Ramos R (2014) Informe técnico de la Ermita del Humilladero. Servicio Territorial de Cultura de Avila. Unpublished report

Nireki T (1980) Examination of durability test methods for building materials based on performance evaluation. In: Sereda PJ, Litvan GG (eds) Durability of building materials and components. ASTM STP 691, American Society for Testing and Materials, Philladelphia, pp 31-37

Raimondi V, Lognoli D, Palombi L (2014) A fluorescence lidar combining spectral, lifetime and imaging capabilities for the remote sensing of cultural heritage assets. In: Michel U, Schulz K, Ehlers M, Nikolakopoulos KG, Civco DL (eds) Earth Resources and Environmental Remote Sensing/GIS Applications V. Proceedings of SPIE 9245. Article Number: $92450 \mathrm{~K}$

Sandrolini F, Franzoni E (2006) An operative protocol for reliable measurements of moisture in porous materials of ancient buildings. Build Environ 41:1372-1380

Smith BJ, Gómez-Heras M, McCabe S (2008) Understanding the decay of stone-built cultural heritage. Prog Phys Geogr 32(4):439-461

Steiger M, Siegesmund S (2007) Special issue on salt decay. Environ Geol 52:185-186

Van Ruymbeke M, Tigny V, De Badts E, Garcia-Moreno R, Billen R. (2008). Development and use of a 4D GIS to support the conservation of the Calakmul site. In: Lasaponara, R Masini, N (Eds) Proceedings of the 1st International EARSeL Workshop, Aracne, pp 333-338 